\title{
A total cost perspective of type 1 and 2 diabetes mellitus in two South African medical schemes servicing the public healthcare sector
}

\author{
A M Opperman, PhD, MBA; M de Klerk, MB ChB, DCG, MBA, MMed (Fam Med) \\ Department of Business Management and Administration, Faculty of Economic and Management Sciences, Stellenbosch University, South Africa
}

Corresponding author: A M Opperman (oppermanm@cput.ac.za)

Background. Diabetes is increasingly becoming a public health concern in South Africa (SA). There are limited available data on the costs of diabetes.

Objectives. To provide a total cost perspective of diabetes using medical scheme claims data from two SA medical schemes servicing the public healthcare sector in 2015 and 2016.

Methods. We analysed data from 2363 diabetes patients. Direct diabetes care costs included medication, consumables, hospitalisation and routine laboratory tests. Indirect costs were calculated by allocating economic costs related to disability-adjusted life years.

Results. The mean (standard deviation) age was 65.8 (13.4) years and women comprised 51\% of the group. Hospitalisation (64.7\% in 2015 and $65.5 \%$ in 2016) and medication (31.0\% in 2015 and $21.1 \%$ in 2016) contributed the most to total direct costs. Total direct diabetes care costs mounted to ZAR2 452 per patient in 2015 and ZAR2 486 in 2016. Indirect costs were ZAR17 223 per patient in 2015 and ZAR18 711 in 2016. When direct and indirect costs were combined, the costs accrued to ZAR27.9 billion (ZAR19 675 per patient) in 2015 and ZAR29.9 billion (ZAR21 197 per patient) in 2016, representing $0.688 \%$ and $0.689 \%$ of the SA gross domestic product over the 2 years, respectively.

Conclusions. Diabetes and its associated costs hold significant implications for the healthcare sector and the country's economy. Large numbers of diabetic individuals remain undiagnosed and the true costs of diabetes might even be higher.

S Afr Med J 2021;111(7):635-641. https://doi.org/10.7196/SAMJ.2021.v111i7.15169

Diabetes mellitus is a chronic degenerative disease associated with a substantially increased risk of chronic complications and comorbidities, which subsequently affect life expectancy and quality of life. ${ }^{[1]}$ Diabetes is increasingly becoming a public healthcare concern in South Africa (SA). In 2013, diabetes was only the fifth leading cause of death among the population but has increased to second place in 2015 (5.4\% of total mortality) and 2016 (5.5\% of total mortality). ${ }^{[2,3]}$ The International Diabetes Federation (IDF) atlas reported that the prevalence of diabetes was $8.3 \%$ in $\mathrm{SA}^{[4]}$ while Bertram et al. ${ }^{[5]}$ reported levels as high as $9 \%$ in 2009 . The IDF further projects that the percentage of the SA population with diagnosed diabetes will increase to $9.9 \%$ by $2035 .{ }^{[4]}$ Although the reported prevalence of diabetes in SA is similar to the global average of $8.8 \%$, it is estimated that undiagnosed diabetes cases vary between 0.908 and 3.085 million. $^{[4]}$

International studies have shown that both type 1 and type 2 diabetes impose a substantial direct and indirect financial burden on the economy of countries. ${ }^{[6-9]}$ Bommer et al. ${ }^{[10]}$ estimated that the global economic burden of diabetes was USD 1.31 trillion, or $1.8 \%$ of the world gross domestic product (GDP) in 2015. Notably, indirect costs accumulated to $34.7 \%$ of the overall global economic burden of diabetes. The analysis further reported that the total cost of diabetes in sub-Saharan Africa (SSA) was USD19.45 billion, or 0.7\% of the region's GDP.

The direct healthcare costs of diabetes represent medical resource utilisation, which embraces both intervention and follow-up care including hospitalisation, specialist and general practitioner care, medication, consumables, rehabilitation, outpatient care, treatment of comorbidities and diet therapy. ${ }^{[11]}$ According to Bommer et al. ${ }^{[10]}$ developing countries such as those in SSA spend $\sim 0.4 \%$ of their GDP on direct diabetes cost.

The indirect healthcare costs of diabetes refer to expenses incurred as a result of reduction or cessation of work productivity caused by morbidity and mortality associated with diabetes. ${ }^{[12]}$ Reduced productivity is typically interrelated with work days missed due to absenteeism, reduced work force participation resulting from chronic disability as well as work years lost as a consequence of early mortality associated with diabetes. ${ }^{[8]}$ Indirect diabetes costs accumulated to $0.3 \%$ of GDP in SSA in 2015. ${ }^{[10]}$ Although no specific costing data are available for $\mathrm{SA}$, the aforementioned international trends should be similar for the population in SA. It is clear that SA needs to make informed future projections to plan for increasing healthcare costs as well as appropriate infrastructure that may be associated with diabetes mellitus. The aim of this study was to use the recent historical data (2015 - 2016) of two public sector entities to estimate the total cost perspective of type 1 and 2 diabetes in the SA context.

\section{Methods}

Direct costs

Secondary quantitative data were utilised to estimate the direct and out-of-pocket (OOP) expenses related to type 1 and type 2 diabetes from two medical schemes servicing the public sector. Data collection for direct costs and OOP expenses were based on a retrospective review of membership claims relating to diabetes services and expenditures consumed by medical scheme members during the period 1 January 2015 to 31 December 2016. Ethical clearance was 
obtained from the University of Stellenbosch Human Research Ethics Committee (ref. no. USB-2018-7985).

Diabetic patients were identified from the medical claim records based on the primary ICD-10 diagnostic codes for diabetes, which included the E10, E11, E13 and E14 codes. Comorbidities and complications were identified by secondary diagnostic codes. It was also computed whether the resources used to treat diabetes and the associated conditions were for in-hospital or out-of-hospital treatment. Medications and diabetic consumables were identified by the use of National Pharmaceutical Product Index (NAPPI) codes. Direct costs extracted from the medical claims included consultations with healthcare professionals, hospitalisation, medication, laboratory testing and complications. The changes in costs between 2015 and 2016 were not adjusted for medical inflation. These components were calculated as follow:

\section{a. Medical consultations \\ TCC $=\mathrm{NC} \times \mathrm{CC} \times \mathrm{DM}$ (adapted from Barceló et al. ${ }^{[13]}$ ) where \\ TCC total cost of consultations \\ NC number of consultations per patient \\ CC average cost of a consultation with a physician \\ $\mathrm{DM}$ number of diabetes patients under care}

\section{b. Hospitalisation}

Hospitalisation costs included all resources and services consumed in hospital but excluded hospital accommodation costs.

$\mathrm{TCH}=\mathrm{NH} \times \mathrm{LH} \times \mathrm{CH} \times \mathrm{DM}^{[14]}$ where

TCH total cost of hospitalisation

$\mathrm{NH}$ annual number of hospitalisations per patient

$\mathrm{CH}$ average cost of hospitalisation per patient

DM number of diabetes patients hospitalised

\section{c. Oral hypoglycaemic agents}

Types of oral hypoglycaemic agents available in SA included biguanides, meglitinides, sulfonylureas, thiazolidinediones, alpha glucosidase inhibitors, dipeptidyl peptidase inhibitors, ergot alkaloids, sodium-glucose co-transporter 2 inhibitors (SGLT2 inhibitors), and a combination of hypoglycaemic medications. Costs for all hypoglycaemic agents utilised during the year were aggregated and divided by the number of patients for whom data were available to calculate the direct cost per person.

\section{d. Insulin}

Types of insulin available in SA included glulisine, lispro, aspart, glargine, detemir, degludec, isophane, premixed insulins and other injectable diabetes medications such as incretin mimetics (exanatide, liraglutide and dulaglutide) and amylin analogues (pramlintide acetate). Costs for all insulin utilised during the year were aggregated and divided by the number of patients for whom data were available to calculate the direct cost per person.

\section{e. Routine laboratory testing}

Routine laboratory testing for diabetes included oral glucose tolerance tests, glycated haemoglobin, fasting insulin, fasting blood glucose, micro-albumin, lipid profiles, creatinine, urea, urine protein test, etc.

$\mathrm{TCE}=\left(\right.$ Test $_{1}+$ Test $_{2}+$ Test $_{3} \ldots$. Test $\left._{\mathrm{n}}\right) \times \mathrm{DM}^{[15]}$ where

Test different laboratory tests

TCE total cost of examinations

DM total diabetes patients who underwent the specified tests

\section{f. Diabetes consumables}

Tcon $=$ Ncon $\times$ Ccon $\times$ Ocon where

Tcon total cost of consumables

Ncon number of consumable users

Ccon cost per consumable (glucometer, test strips, lancets, insulin needles, syringes, glucagon kits, insulin pump consumables (i.e. reservoirs and infusion sets))

Ocon estimated number of each consumable used per patient per year

\section{g. Hospital accommodation}

Accommodation costs were calculated for hospital stay in general wards, intensive care units (ICUs), medium intensity care and high care (HC) wards which lasted 2 days or longer. Costs for all hospital accommodation during the year were aggregated and divided by the number of patients for whom data were available to calculate the direct costs per person.

\section{h. Comorbidities and complications}

Comorbidities considered in the present study were cardiovascular disease (CVD), cerebrovascular and vascular disease, ophthalmic diseases and renal diseases while complications included coma and ketoacidosis, retinopathy, nephropathy and multiple complications. The ICD-10 codes considered for comorbidities and complications are indicated in Table 1. Neurological complications were not considered since very few claims were reported. All claims associated with comorbidities and complications were analysed in the same manner as described in points above.

It should be noted that the implicated data extraction methods (a-f) were recommended; however, data used for statistical analysis depended on the availability of such data from the medical claim records. Common data collection and processing errors that might impair the accuracy and reliability of medical scheme data included incomplete claims data, errors in coding of diagnostic data, patients who fail to seek care for their condition and patients treated outside their insurance/medical scheme. ${ }^{[16]}$

Table 1. Comorbidities and complications

Group
Cardiovascular disease
Cerebrovascular and vascular disease
Ophthalmic disease
Renal disease
Coma and ketoacidosis
Ophthalmic complications
Peripheral circulatory complications
Multiple complications




\section{Out-of-pocket expenses}

OOP expenses refer to the part of the medical account that medical schemes or insurance companies do not pay and has to be paid from a patient's own pocket. ${ }^{[17]} \mathrm{OOP}$ expenses were calculated as follow:

OOP payments $=$ amount claimed from scheme - amount paid by scheme. ${ }^{[18]}$

Data for the same diabetic patients were analysed for both 2015 and 2016. Statistical analysis was conducted using SPSS software, version 25.0 (IBM Corp., US). Descriptive statistics were presented as mean with $95 \%$ confidence intervals. The Mann-Whitney $U$ test was performed to compare costs between 2015 and 2016 since costs data were typically skewed as a result of a limited number of patients incurring particularly high costs. The two-sided level of significance was established at $p \leq 0.05$.

\section{Indirect costs}

Indirect cost calculations were based on costs related to the disabilityadjusted life years (DALYs) resulting from diabetes in SA. The DALYs are a combined measure of health quality and quantity with the aim to capture the adverse consequences of premature mortality (years of life lost (YLL)) alongside the burden of morbidity (years lost due to disability (YLD)) for the extent of the illness. ${ }^{[19]}$ The DALYs for diabetes in SA were derived from Bertram et al. ${ }^{[5]}(\mathrm{YLD}=78$ 900) and Groenewald et al. ${ }^{[20]}(\mathrm{YLL}=272000)$. Bertram et al. ${ }^{[5]}$ further reported that $64 \%$ of YLD was lost from diabetes alone, $24 \%$ from retinopathy, $9 \%$ from stroke, $7 \%$ from ischaemic heart disease and $6 \%$ from amputations. Since the YLD was reported for 2009 and YLL for 2015, numbers were adjusted for annual escalations. According to the Institute for Health Metrics and Evaluation Global Burden of Disease (IHME GBD) report, ${ }^{[21]}$ the YLL and YLD increased by $2.33 \%$ and $2.3 \%$, respectively on an annual basis in SA. After this adjustment, the product of the DALY and the gross domestic product (GDP) per capita was calculated to estimate the approximate economic value lost that an average individual contributes to society per year. ${ }^{[22]}$ Two other scenarios as described by Kirigia et al. ${ }^{[23]}$ and Murray and Lopez ${ }^{[19]}$ were also considered (Appendix 1 and 2: http:// samj.org.za/public/sup/15169.pdf). However, since the approaches of Bertram et al. ${ }^{[5]}$ and Groenewald et al. ${ }^{[20]}$ were representative of the SA population, these indirect cost calculations will be reported in the results section.

\section{Results}

Sample characteristics

Since data of the same individuals were utilised over the 2-year period, only the demographic data for 2015 are reported (Table 2). Of the 2363 patients, $89.3 \%$ had type 2 diabetes, which is reflective of the usual global distribution between type 1 and type 2 diabetics. The mean (standard deviation (SD)) age was 65.8 (13.4) years while $54.7 \%$ of patients were younger than 69 years. Women comprised $51.4 \%$ of the group.

The most common comorbidity was cardiovascular disease ( $n=1850$ for both 2015 and 2016) followed by ophthalmic disease ( $n=184$ in 2015 and $n=190$ in 2016), and the most prevalent complications included ophthalmic ( $n=137$ in 2015 and $n=132$ in 2016) as well as multiple complications ( $n=89$ in 2015 and $n=66$ in 2016) (Appendix 2: http://samj.org.za/public/sup/15169.pdf).

Overall direct costs irrespective of secondary conditions Main medical resource consumption contributing to the overall diabetes costs (medication and consumables, laboratory tests, physician's consultations, hospital accommodation, in- as well as out-

\begin{tabular}{ll} 
Table 2. Demographic data $(\mathbf{N = 2 ~ 3 6 3 )}$ & \\
\hline Patient characteristics & $\boldsymbol{n}(\%)^{*}$ \\
\hline Age (years), mean (SD) & $65.8(13.4)$ \\
$\quad<40$ & $49(2.1)$ \\
$40-49$ & $250(10.6)$ \\
$50-59$ & $509(21,5)$ \\
$60-69$ & $485(20.5)$ \\
$70-79$ & $685(29.0)$ \\
$\geq 80$ & $385(16.3)$ \\
Gender & \\
$\quad$ Male & $1149(48.6)$ \\
$\quad$ Female & $1214(51.4)$ \\
Form of diabetes & \\
Type 1 & $252(10.7)$ \\
Type 2 & $2111(89.3)$ \\
SD = standard deviation. & \\
*Unless otherwise specified. &
\end{tabular}

of-hospital patient cost) are illustrated in Fig. 1 (Apprendix 3: http:// samj.org.za/public/sup/15169.pdf).

The total medical resources consumed per diabetic patient were ZARR60 125 (95\% confidence interval (CI) 55004 - 65 247) in 2016 compared with ZAR53 216 (95\% CI 48491 - 57 937) in 2015. These costs reflect all costs irrespective of the disease (besides diabetes) the patient was treated for. Laboratory services and in-hospital costs were all considerably higher in 2016 compared with $2015(p<0.05)$. Additionally, hospitalisation contributed 64.7\% (ZAR37 409; 95\% CI 31385 - 43433 ; $n=614)$ to total cost in 2015 and increased significantly (ZAR39 361; 95\% CI 34614 - 44 108; $n=742$ ) in 2016 $(p<0.05)$.

When considering only costs to treat diabetes as a primary condition, the mean cost of medication (oral hypoglycaemic agents), insulin, routine laboratory and consumable costs accumulated to ZAR5 297 (95\% CI 4996 - 5 599) per patient in 2015 and ZAR5 213 (95\% CI 4925 - 5 501) in 2016 (Fig. 2). However, when excluding the cost of insulin from the equation, the mean cost per patient become ZAR2 452 (95\% CI 2366 - 2 540) in 2015 and ZAR2 486 (95\% CI 2396 - 2 576) in 2016. The mean cost of insulin contributed ZAR8 152 (95\% CI $7585-8$ 720) in 2015 and ZAR7 542 (95\% CI $7061-8023)$ in 2016 to the total costs of diabetes care for patients on insulin (Appendix 2: http://samj.org.za/public/sup/15169.pdf). None of the costs changes between 2015 and 2016 were significant.

\section{Comorbidities and complications}

Costs related to comorbidities and complications of diabetes are depicted in appendices 2, 4 and 5 (http://samj.org.za/public/ sup/15169.pdf). The total number of patients with comorbidities remained similar between 2015 and 2016, with per patient costs of ZAR16 400 (95\% CI 12876 - ZAR19 924) in 2015 and ZAR17 853 (95\% CI 14855 - 20 850) in 2016. The most costly comorbidities were renal conditions followed by cerebrovascular and vascular disease. In-hospital costs were dominated by cardiovascular, cerebrovascular and vascular disease as well as renal conditions while out-of-hospital costs were mostly associated with renal conditions amounting to ZAR88 821 (95\% CI 49486 - 128 156) in 2015 and ZAR83 295 (95\% CI 52938 - 113652$)$ in 2016 per patient.

Costs of diabetic complications did not change significantly between 2015 and 2016. The biggest contributor to total costs of complications was peripheral circulatory complications 


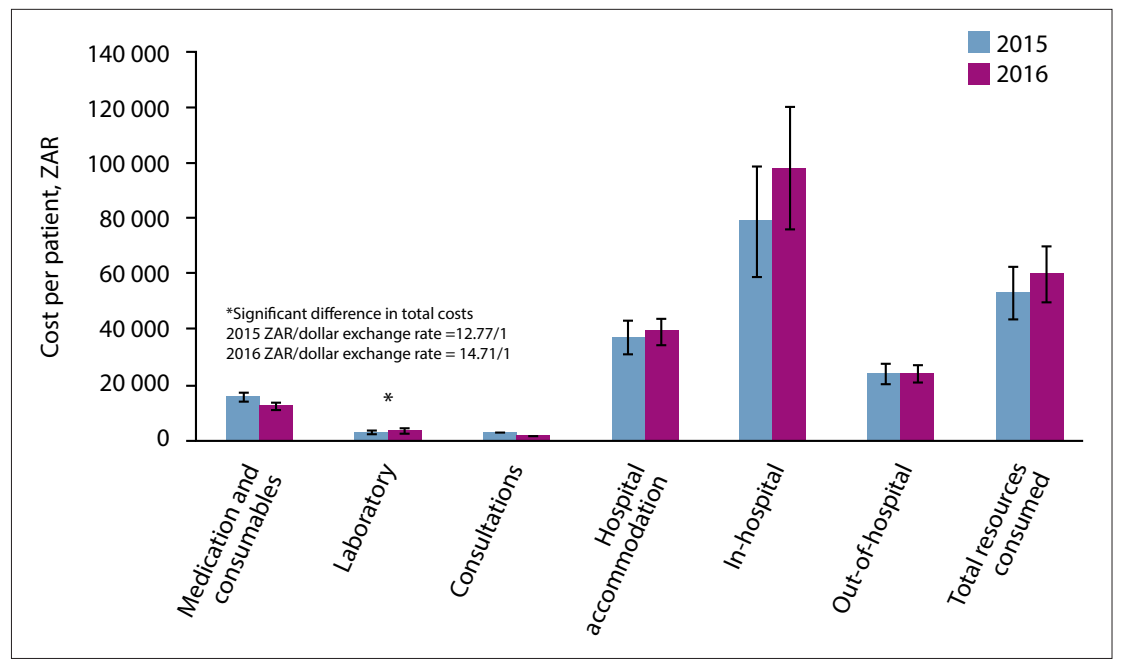

Fig. 1. Medical resource consumption including all conditions secondary to diabetes.

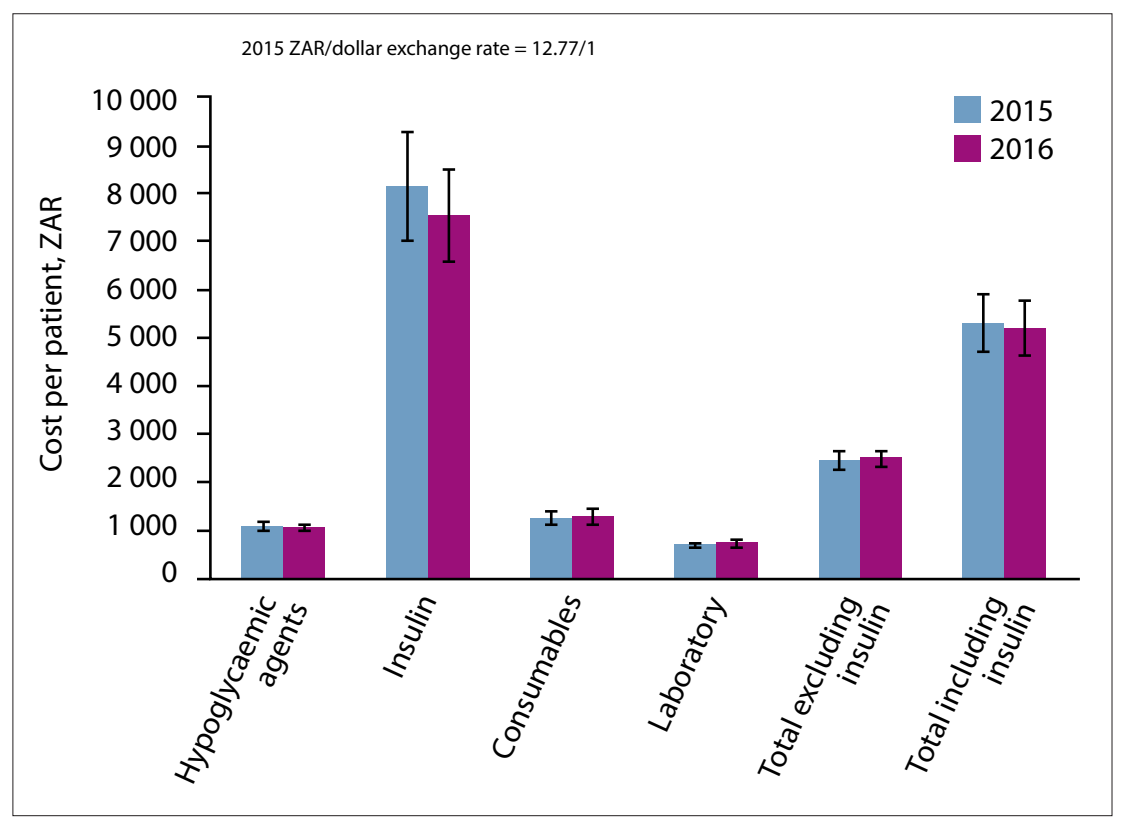

Fig. 2. Total costs of diabetes care.

(ZAR21 084; 95\% CI 10652 - 31 515) in 2015 and ZAR16 673 (95\% CI 6943 - 26 403) in 2016) as well as ophthalmic complications (ZAR10 397 (95\% CI 7253 - 13 541) in 2015 and ZAR7 572 (95\% CI 5089 - 10 047) in 2016). The same observation was recorded for in-hospital costs for peripheral circulatory complications (ZAR31 980; 95\% CI 17502 - 46 458) in 2015 and ZAR31 808 (95\% CI 14582 - 49 034) in 2016 and ophthalmic complications (ZAR25 436; 95\% CI 18799 - 32 073) in 2015 and ZAR25 784 (95\% CI 15872 - 35 695) in 2016. Ophthalmic complications were the major contributor to out-of-hospital claims (ZAR3 495; 95\% CI 2317 - 4 673) in 2015 and ZAR3 201 (95\% CI 2362 - R4 040) in 2016. Healthcare costs for diabetics without complications or comorbidities were noticeably lower than for patients with complications and/or comorbidities. Total claims for patients without complications amounted to ZAR1 296 (95\% CI $881-1790)$ in 2015 and ZAR953 (95\% CI 846 - 1059$)$ in 2016 per patient.

\section{Hospital \\ accommodation}

Between 18 and $20 \%$ of diabetes patients in the study group were admitted to hospital for 2 days or longer during 2015 and 2016. The admission rate was similar between type 1 and type 2 diabetes over the 2 -year period. The average number of days spent in hospital was 7.7 (95\% CI 6.7 - 8.8) days in 2015 and remained comparable in 2016 (6.6 days; $95 \%$ CI 5.9 - 7.4). The mean age of male patients admitted to hospital increased significantly $(p<0.05)$ from 66.2 years (95\% CI 64.4 - 68.0) in 2015 to 70.2 years $(95 \%$ CI $68.5-72.1)$ in 2016. Accompanying the difference in age was a significant increase $(p<0.05)$ in accommodation cost from ZAR39 971 (95\% CI 31950 - 47 992) in 2015 to ZAR70 743 (95\% CI 57352 - 84 135) in 2016.

The cost of accommodation was significantly higher $(p<0.05)$ for female patients (ZAR49 707; 95\% CI 40184 59 229) than for male patients (ZAR39 971; 95\% CI 31950 - 47992$)$ in 2015, and there was a significant escalation $(p<0.05)$ in accommodation costs for females between 2015 (ZAR49 707; 95\% CI 40184 - 59 229) and 2016 (ZAR65 536; 95\% CI 54686 76 386). Total accommodation costs for the group increased significantly $(p<0.05)$ from ZAR44 960 (95\% CI $38714-51206)$ in 2015 to ZAR68 037 (95\% CI 59517 - 76 558) in 2016, representing an increase of $51.3 \%$ (Table 3).

\section{Indirect costs}

Table 4 presents the indirect diabetes cost estimates for the country in 2015 and 2016. Total indirect costs amounted to ZAR27.1 billion in 2015 and ZAR29.3 billion in 2016, of which almost $75 \%$ over both years could be attributed to premature mortality. Indirect cost per patient was ZAR17 223 in 2015 and increased to ZAR18 711 in 2016. Indirect costs contributed substantially to the burden of diabetes costs in SA $(0.669 \%$ and $0.676 \%$ of GDP in 2015 and 2016, respectively).

\section{Direct and indirect costs combined}

Because of the large variation in costs and relatively small number of patients experiencing comorbidities (except for CVD) and diabetic complications, it was not possible to extrapolate these figures to the larger SA population. However, the cost estimations for total insulin costs, diabetes care in general as well as the costs associated with type 2 diabetes and CVD are indicated in Table 5.

When extrapolating the figures to the broader population, it was assumed that $90 \%$ of diabetes patients needed anti-diabetic agents, consumables and routine laboratory tests, of which the costs were estimated to be between ZAR3.48 billion in 2015 and ZAR3.51 billion in 2016 (Table 5). On addition of indirect costs, the diabetes care figures escalated to ZAR27.9 billion in 2015 and ZAR29.9 billion in 2016. Approximately $10 \%$ of the diabetic population uses insulin. Insulin costs varied between ZAR1.28 billion in 2015 and ZAR1.21 billion in 2016. In terms of CVD and type 2 diabetes, direct cost estimations were ZAR4.66 billion in 2015 and ZAR4.92 billion in 2016. OOP for 
Table 3. Hospital accommodation costs for 2 or more days' stay

\begin{tabular}{|c|c|c|c|c|}
\hline & Gender & 2015, mean $(95 \% \mathrm{CI})$ & 2016, mean $(95 \% \mathrm{CI})$ & \% Difference \\
\hline \multirow{3}{*}{$n$} & Female & 226 & 211 & -6.6 \\
\hline & Male & 215 & 195 & -9.3 \\
\hline & Total & 441 & 406 & -7.9 \\
\hline \multirow{2}{*}{ Type diabetes } & Type 1 & 54 & 53 & -1.9 \\
\hline & Type 2 & 387 & 353 & -8.8 \\
\hline \multirow{3}{*}{ Age (years) } & Female & $67.4(65.7-69.0)$ & $68.5(66.9-70.1)$ & 1.6 \\
\hline & Male & $66.2(64.4-68.0)$ & $70.2(68.5-72.1)$ & $6.0^{*}$ \\
\hline & Total & $66.8(65.6-68.0)$ & $69.3(68.1-70.5)$ & $3.7^{\star}$ \\
\hline \multirow{3}{*}{ Days in hospital } & Female & $7.7(6.7-8.7)$ & $6.4(5.5-7.3)$ & -16.9 \\
\hline & Male & $7.2(5.9-8.5)$ & $6.9(5.7-8.1)$ & -4.2 \\
\hline & Total & $7.7(6.7-8.7)$ & $6.6(5.9-7.4)$ & -14.3 \\
\hline \multirow{3}{*}{ Amount (ZAR) } & Female & $49707(40184-59229)$ & $65536(54686-76386)$ & $31.8^{*}$ \\
\hline & Male & $39971(31950-47992)$ & $70743(57352-84135)$ & $77.0^{*^{\dagger}}$ \\
\hline & Total & $44960(38714-51206)$ & $68037(59517-76558)$ & $51.3^{*}$ \\
\hline
\end{tabular}

Table 4. Costs related to the disability-adjusted life years attributed to diabetes during 2015 and 2016

\begin{tabular}{|c|c|c|c|c|}
\hline & Annual change, $\%$ & DALY & 2015 & 2016 \\
\hline YLD & $2.3^{*}$ & $\begin{array}{l}78900^{+} \\
(2009)\end{array}$ & 91603 & 93418 \\
\hline YLL & $2.33^{*}$ & $\begin{array}{l}272000^{\ddagger} \\
(2015)\end{array}$ & 272000 & 278338 \\
\hline DALY (YLD + YLL) & - & - & 363603 & 371755 \\
\hline GDP per capita & - & - & ZAR74 $663^{5}$ & ZAR79 $066^{5}$ \\
\hline $\mathrm{DALY} \times \mathrm{GDP}$ & - & - & ZAR27 147683322 & ZAR29 393196643 \\
\hline Number of diabetics in SA & - & - & $1576186^{9}$ & $1570867^{9}$ \\
\hline Indirect cost per patient per year & - & - & ZAR17 223 & ZAR18 711 \\
\hline Nominal GDP per year & - & - & ZAR4 $057539800000^{\|}$ & ZAR4 $350629600000^{* *}$ \\
\hline$\%$ of GDP & - & - & 0.669 & 0.676 \\
\hline \multicolumn{5}{|c|}{ 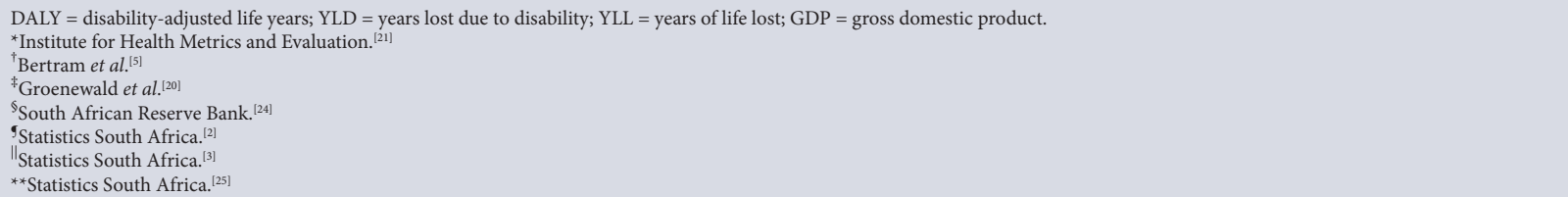 } \\
\hline
\end{tabular}

this group was ZAR192 million in 2015 and ZAR232 million in 2016 (calculations available on request).

\section{Discussion}

It is clear from the preceding analysis that diabetes and its associated costs hold significant implications for the SA healthcare sector as well as the country's economy. Most costs increased between 2015 and 2016, and this can mainly be attributed to inflation. It is generally accepted in the industry that medical inflation is $2-3 \%$ higher compared with the Consumer Price Index (CPI; 4.6\% for 2015). ${ }^{[27]}$

The cost of accommodation during hospitalisation appeared to be the major expense for medical resource consumption in this present study. Even when medical inflation is taken into account, total hospital accommodation cost increased significantly between 2015 and 2016, and might be attributed to the increase in patients developing renal comorbidities and costs related to multiple complications. The subsequent comorbidities and complications contributed to a number of outliers for the period of hospitalisation as well as the total cost of accommodation and hence added disproportionately to costs in 2016. Additionally, more patients were admitted to ICU and HC units and stayed for longer periods in 2016. Male patients ( $n=93$ ) spent an average of 8 days in ICU and HC units compared with 60 patients who stayed for 6 days in 2015. Female patients $(n=82)$ spent an average of 7 days in the ICU and HC units in 2016 compared with 58 patients who stayed for 6 days in 2015. Medication was also another major contributor to medical resource consumption. Notably, the total cost of diabetes care was considerably higher than medical inflation between 2015 and 2016 $(16.0 \%$ v. $7.6 \%){ }^{[28]}$ The numbers of direct costs can be adjusted for compounded medical inflation (23.1\%) between 2017 and 2020 to obtain more recent figures. ${ }^{[29-32]}$

Direct costs associated with comorbidities were highest among renal disease patients both in- and out-of-hospital followed by cerebrovascular and vascular disease. Even though CVD among diabetes patients was not the most costly, it far outnumbered the other comorbidities. Renal complications were more costly followed by ophthalmic complications. The number of patients developing comorbidities and complications (excluding ophthalmic and multiple 
Table 5. Extrapolation of combined direct and indirect costs

\begin{tabular}{|c|c|c|c|c|}
\hline & \multicolumn{2}{|r|}{2015} & \multicolumn{2}{|r|}{2016} \\
\hline & $n$ & Mean $(95 \%$ CI $)$ & $n$ & Mean $(95 \%$ CI $)$ \\
\hline \multicolumn{5}{|l|}{ Cost of insulin } \\
\hline Insulin ${ }^{*}$ & 808 & ZAR8 $152(7585-8720)$ & 824 & ZAR7 542 (7 $061-8023)$ \\
\hline Total & $157619^{\dagger}$ & $\begin{array}{l}\text { ZAR1 } 284910088 \\
(1195540115-1374437680)\end{array}$ & $157087^{\ddagger}$ & $\begin{array}{l}\text { ZAR1 } 184750154 \\
\left(\begin{array}{lll}1 & 109191307-1260309001\end{array}\right)\end{array}$ \\
\hline \multicolumn{5}{|l|}{$\begin{array}{l}\text { Cost of oral hypoglycaemic agents, } \\
\text { consumables, routine laboratory tests } \\
\text { and indirect costs }\end{array}$} \\
\hline Direct cost of diabetes care ${ }^{*}$ & 2312 & ZAR2 452 (2 366 - 2 540) & 2297 & ZAR2 486 (2 396 - 2 576) \\
\hline Sub total & $1418567^{\Im}$ & $\begin{array}{l}\text { ZAR3 } 478326284 \\
(3356329522-3603160180)\end{array}$ & $1413780 d^{9}$ & $\begin{array}{l}\text { ZAR3 } 514657080 \\
(3387416880 \text { - } 3641897280)\end{array}$ \\
\hline SA health expenditure per year & - & ZAR348 948422800 & - & ZAR387 206034400 \\
\hline$\%$ of health expenditure per year & - & 0.997 & - & 0.908 \\
\hline Indirect costs & $1418567^{5}$ & ZAR17 223 & 1413 780d' & ZAR18 711 \\
\hline Subtotal & - & ZAR24 431986330 & - & ZAR26 453243193 \\
\hline Total & - & ZAR27 910312614 & - & ZAR29 967900273 \\
\hline Nominal GDP per year & - & ZAR4 057539800000 & - & ZAR4 350629600000 \\
\hline$\%$ of GDP & - & 0.688 & - & 0.689 \\
\hline Cost per patient & - & ZAR19 675 & - & ZAR21 197 \\
\hline \multicolumn{5}{|l|}{$\begin{array}{l}\text { Direct and indirect costs of type } 2 \\
\text { diabetes with CVD }\end{array}$} \\
\hline Direct costs of type 2 diabetes $+\mathrm{CVD}^{*}$ & 1850 & ZAR10 $200(8008$ - 12 392) & 1850 & ZAR10 802 (8 866 - 12 737) \\
\hline Subtotal & $456779 \|$ & $\begin{array}{l}\text { ZAR4 } 659145800 \\
(3657886232-5660405368)\end{array}$ & $455237 f^{* *}$ & $\begin{array}{l}\text { ZAR4 } 917470074 \\
\left(\begin{array}{l}4036131242-5798353669\end{array}\right)\end{array}$ \\
\hline SA health expenditure per year & - & ZAR348948 422800 & - & ZAR387 206034400 \\
\hline$\%$ of health expenditure per year & - & 1.335 & - & 1.270 \\
\hline Indirect costs & 1850 & 17223 & 1850 & 18711 \\
\hline Subtotal & $456779 \|$ & ZAR7 867104717 & $455237 f^{* *}$ & ZAR8 517939507 \\
\hline Total & - & ZAR12 526250517 & - & ZAR13 435409581 \\
\hline Nominal GDP per year & - & ZAR4 057539800000 & - & ZAR4 350629600000 \\
\hline$\%$ of GDP & - & 0.309 & - & 0.309 \\
\hline Cost per patient & - & ZAR27 423 & - & ZAR29 513 \\
\hline \multicolumn{5}{|c|}{ 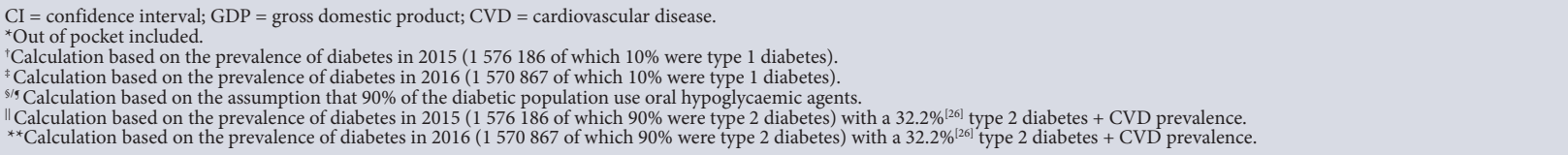 } \\
\hline
\end{tabular}

complications) increased from 2015 to 2016. It is therefore vital that these patients achieve optimal glycaemic control to prevent future deterioration of their health status.

Renal comorbidities were associated with the highest OOP payments. Other OOP payments were relatively small in relation to total costs. This can be attributed to the fact that diabetes as well as the respective comorbidities and complications are prescribed minimum benefits (PMBs). PMBs refer to a set of defined medical benefits that provide access to certain minimum health services irrespective of the benefit option scheme members may have selected. The medical scheme therefore has to cover the costs related to the diagnosis, treatment and care of diabetes as well as the stipulated comorbidities and complications.

On extrapolation of the current data to the larger SA diabetes community, it was estimated that direct and indirect costs of only the diabetes care expenses (hypoglycaemic agents, consumables and routine laboratory tests) accounted for $0.683 \%$ of the country's GDP in 2015 and $0.696 \%$ in 2016. Indirect costs were estimated to form the largest portion of total diabetes costs and contributed to $88 \%$ of costs in 2015 and $87 \%$ in 2016. This contribution may decrease if hospitalisation accommodation costs could be accounted for. Almost $75 \%$ of indirect costs could be attributed to premature mortality (YLL) over the 2 years.

When combining costs of diabetes care with comorbidities such as CVD, the costs per patient increased dramatically. According to the meta-analysis by Einarson et al. ${ }^{[26]}$ the global prevalence of CVD in type 2 diabetes patients is $32.2 \%$. This figure has been indicated for developed countries and might therefore be a conservative estimate for the SA population. Nevertheless, these estimations from Einarson et al. ${ }^{[26]}$ created figures of ZAR12.3 billion (ZAR27 017 per patient) in 2015 and ZAR14.0 billion (ZAR30 759 per patient) in 2016, which represent $1.28 \%$ and $1.42 \%$ of total health expenditure in 2015 and 2016 , respectively.

\section{Study strengths and limitations}

Regarding the strengths of the present study, the total number of diabetics in the group were adequate to provide a decent estimation of diabetic care costs as well as the cost of type 2 diabetes with CVD 
in 2015 and 2016. To our knowledge, this is the first study in SA to utilise medical scheme claims data in an attempt to estimate direct diabetes costs.

One of the study limitations was a substantial number of claims that could not be allocated to a specific condition because of the use of nonspecific ICD-10 codes such as the Z00.8 code or a number of laboratory examinations (e.g. Z01.7 for full blood counts). Even when considering tariff descriptions, it was not possible to allocate these claims. The current data could not account for aspects such as absenteeism, presenteeism and productivity. Omitting the stated direct and indirect costs is likely to grossly underestimate the true costs incurred by diabetics. Lastly, not all diabetics in SA are members of medical schemes, which may overestimate the cost of diabetes in the public healthcare sector. The public healthcare system serves around $82.5 \%$ of the population while the private sector serves $17.5 \%{ }^{[32]}$ Additionally, medical scheme membership is not homogeneous and it was therefore not possible to account for the different benefit options in our analysis. It should however be noted that all schemes should cover PMBs.

It is therefore recommended to expand the present study by including the data of other public sector schemes as well as the private sector schemes operational in the country. This should ensure a more holistic picture of the true costs incurred by diabetics in the SA. The reported results are therefore not intended to guide decisions on health policy but rather to increase awareness among policy-makers and the SA public on the negative impact of diabetes on the SA economy.

\section{Conclusions}

The foregoing discussion highlights the financial burden that diabetes places on the SA economy. Since a large number of diabetes cases remain undiagnosed and untreated, the true economic impact of diabetes is almost impossible to project. What is certain is that the prevalence of diabetes is on the rise and costs associated with the disease will keep escalating. Additionally, special attention needs to be placed on the increasing costs of type 2 diabetes and CVD but also on the enormous burden of other comorbidities such as renal and cerebrovascular diseases. The only way to prevent the devastating consequences of diabetes is lifestyle changes, early detection of the disease in its pre-diabetic phase as well as optimal glucose control once diabetes is diagnosed. SA simply cannot afford a fullblown diabetes epidemic as well as its associated comorbidities and complications considering the current economic climate.

Declaration. This study was conducted in partial fulfilment for the degree of Master of Business Management and Administration at the University of Stellenbosch Business School.

Acknowledgements. None.

Author contributions. Both authors contributed equally to the manuscript.

Funding. None.

Conflicts of interest. None.
1. American Diabetes Association. Diagnosis and classification of diabetes mellitus. Diabetes Care 2013;36(SUPPL.1):67-74. https://doi.org/10.2337/dc13-S067

2. Statistics South Africa. Mortality and causes of death in South Africa, 2015: Findings from death . Statistics South Africa. Mortality and causes of death in Sou
notification. Statistical release P0309.3. Stats SA: Pretoria, 2017.

3. Statistics South Africa. Mortality and causes of death in South Africa: Findings from death notification, 2016. Stats SA: Pretoria, 2018.

4. International Diabetes Federation. IDF Diabetes Atlas. 8th ed. International Diabetes Federation. Brussels, Belgium: International Diabetes Federation; 2017. 150. http://www.diabetesatlas.org/

5. Bertram MY, Jaswal AVS, Van Wyk VP, et al. The non-fatal disease burden caused by type 2 diabetes in South Africa, 2009 Bertram Global Health Action. Glob Health Action 2013;19244(6):19244. https:// doi.org/10.3402\%2Fgha.v6i0.19244

6. Jönsson B. Revealing the cost of Type II diabetes in Europe. Diabetologia 2002;45(1):S5-S12. https:// 6önsson B. Revealing the cost of Type
doi.org/10.1007/s00125-002-0858-x

7. Lee CMY, Colagiuri R, Magliano DJ, et al. The cost of diabetes in adults in Australia. Diabetes Res Clin Lee CMY, Colagiuri R, Magliano DJ, et al. The cost of diabetes in adults in
Pract 2013;99(3):385-390. https://doi.org/10.1016/j.diabres.2012.12.002

8. Peters ML, Huisman EL, Schoonen M, Wolffenbuttel BHR. The current total economic burden of diabetes mellitus in the Netherlands. Neth J Med 2017;75(7):281-297.

9. Sørensen M, Arneberg F, Line TM, Berg TJ. Cost of diabetes in Norway 2011. Diabetes Res Clin Pract 2016;122:124-132. https://doi.org/10.1016/j.diabres.2016.10.012

10. Bommer C, Heesemann E, Sagalova V, et al. The global economic burden of diabetes in adults aged 2079 years: A cost-of-illness study. Lancet Diabetes Endocrinol 2017;5:423-430. https://doi.org/10.1016/ s2213-8587(17)30097-9

11. Kirch W. Encyclopedia of Public Health. Dordrecht: Springer Netherlands, 2008.

12. Boccuzzi SJ. Indirect healthcare costs. In: Weintraub WS, ed. Cardiovascular Health Care Economics Boccuzzi SJ. Indirect healthcare costs. In: Weintraub WS, ed. Cardiovascular Health Care Economics
Contemporary Cardiology. Totowa: Humana Press, 2003:63-79. https://link.springer.com/ Contemporary Cardiology. Totowa:
chapter/10.1007/978-1-59259-398-9_5

13. Barceló A, Aedo C, Rajpathak S, Robles S. The cost of diabetes in Latin America and the Caribbean. Bull World Health Organ 2003;81(1):19-27. https://doi.org/10.7189/jogh.07.020410

14. Gagliardino JJ, Kleinebreil L, Colagiuri S, et al. Comparison of clinical-metabolic monitoring and outcomes and coronary risk status in people with type 2 diabetes from Australia, France and Latin America. Diabetes Res Clin Pract 2010;88(1):7-13. https://doi.org/10.1016/j.diabres.2009.12.024

15. World Health Organization. Assessing national capacity for the prevention and control of noncommunicable diseases: Global survey. Geneva: WHO, 2013. http://www.who.int/chp/ncd capacity/NCD_CCS_2013_report.pdf?ua $=1$

16. Tyree PT, Lind BK, Lafferty WE. Challenges of using medical insurance claims data for utilisation analysis. Am J Med Qual 2006;21(4):269-275. https://doi.org/10.1177\%2F1062860606288774

17. Fox KM, Grandy S, Group for the SS. Out-of-pocket expenses and healthcare resource utilisation among individuals with or at risk of diabetes mellitus. Curr Med Res Opin 2008;24(12):3323-3329. https://doi.org/10.1185/03007990802520045

18. Council for Medical Schemes. Out of pocket payments by medical scheme members: Research and monitoring. 2015. https://www.medicalschemes.com/files/Research\%20Briefs/RBOPPStudy2013.pd (accessed 12 May 2020).

19. Murray CJL, Lopez AD, Harvard School of Public Health, World Health Organization, World Bank. The global burden of disease : A comprehensive assessment of mortality and disability from diseases The global burden of disease : A comprehensive assessment of mortality and disability from diseases,
injuries, and risk factors in 1990 and projected to 2020. Published by the Harvard School of Public Health on behalf of the World Health Organization and the World Bank, 1996. https://apps.who.int/ Health on behalf of the World Health Organization
iris/handle/10665/41864 (accessed 21 March 2020).

iris/handle/10665/41864 (accessed 21 March 2020).
20. Groenewald P, Bradshaw D, Day C, Laubscher R. Burden of disease. In: Massyn N, Padarath A, Peer N, Day C, editors. District Health Barometer 2016/2017. Durban: Health Systems Trust, 2018:206-226.

21. Institute for Health Metrics and Evaluation. Global burden of disease compare. 2018. http://www. healthdata.org/ (accessed 17 September 2018).

22. Commission of Macroeconomics and Health. Macroeconomics and health: investing in health for economic development. Rev Panam Salud Pública 2001;12:143-144. https://apps.who.int/iris/ handle/10665/42463 (accessed 23 January 2020).

23. Kirigia JM, Sambo HB, Sambo LG, Barry SP. Economic burden of diabetes mellitus in the WHO African region. BMC Int Health Hum Rights 2009;9(1):1-12. https://doi.org/10.1186/1472 $698 \mathrm{x}-9-6$

24. South African Reserve Bank. Online statistical query (historical macroeconomic timeserie information) - South African Reserve Bank. https://www.resbank.co.za/Research/Statistics/Pages/ OnlineDownloadFacility.aspx (accessed 13 September 2018).

25. Statistics South Africa. Financial statistics of provincial government 2015/2016. 2017. Stats SA: Pretoria, 2017. http://www.statssa.gov.za/publications/P9121/P9121.pd

26. Einarson TR, Acs A, Ludwig C, Panton UH. Prevalence of cardiovascular disease in type 2 diabetes: A systematic literature review of scientific evidence from across the world in 2007-2017. Cardiovasc Diabetol 2018;17(1):1-19. https://doi.org/10.1186/s12933-018-0728-6

27. Statistics South Africa. Statistical release P0141 Consumer Price Index. Stats SA: Pretoria, 2015.

28. Alexander Forbes. Medical scheme inflation explained. 2020. www.alexanderforbes.co.za (accessed 28 November 2019)

29. Statistics South Africa. Consumer Price Index. Stas SA: Pretoria, 2017. http://www.statssa.gov.za/ publications/P0141/P0141February2017.pdf

30. Statistics South Africa. Consumer price index. Stats SA: Pretoria, 2019. http://www.statssa.gov.za/ publications/P0141/P0141July2019.pdf

1. Statistics South Africa. Consumer price index. Stats SA: Pretoria, 2018. http://www.statssa.gov.za/ publications/P0141/P0141March2018.pdf

32. Statistics South Africa. Consumer Price Index. Stats SA: Pretoria, 2016. http://www.statssa.gov.za/ publications/P0141/P0141September2016.pdf 